\title{
From Martial Arts to Practice: A Philosophical Examination of the Term Martial Art
}

\author{
LeRon James Harrison \\ University of Oregon
}

\begin{abstract}
The term martial art is used as a heading to discuss a wide range of combative styles; however, the term is deployed in ways that exposes a disconnection between the term and the styles to which it is referring. In this paper, I explore the disconnection between the martial arts and posit that martial art is an oxymoron as described by Michel de Certeau. As an alternative to the oxymoronic use of martial art, I examine two conceptions of practice: the first advanced by Alasdair MacIntyre and applied to martial arts by Charles Hackney; the second advanced by Todd May and amended with ideas from Noël Carroll. The latter conception of practice begins to establish a new way to consider the relationships among the combative styles and how these can be incorporated into the term martial arts, thereby quelling the disconnection between the term and the styles.
\end{abstract}

Keywords: martial arts, practice, paradox, oxymoron, ethics, ontology

\section{Introduction}

Richard Palmer in the introduction to Hermeneutics: Interpretation Theory in Schleiermacher, Dilthey, Heidegger, and Gadamer states "language shapes man's seeing and his thought—both his conception of himself and his world... Far more than man realizes, he channels through language the various facets of his living - his worshipping, loving, social behavior, abstract thought..." Palmer points out that language shapes our actions and thoughts because "human existence as we know it does in fact always involve language;" in other words, human ontology is connected to language (Palmer 1969, 9). By extension, anything that plays a role in human existence is similarly channeled through and shaped by language. Language provides us with the concepts and positions for discussion, but as we use language every day, we tend to overlook the ways that language shapes our discourses and ourselves. This problem of linguistic and discursive oversight, I will argue, is applicable to the term martial art. Martial art is a term people use so frequently that they overlook the ways that the term shapes the discussions we have about the various styles that fall under its heading.

Take for example Daniele Bolelli's discussion of martial arts in his book On the Warrior's Path; in the introduction Bolelli claims that martial arts "are nothing but a ghetto" as they are "restricted to "insiders only." But if martial arts are a ghetto closed off to "insiders only," how did they become that way? The answer is that Bolelli makes martial arts into a ghetto to advance his thesis that martial arts need "an athletic philosophy: a philosophy forged through muscle and heart; a philosophy born out of the union of body and mind, of pragmatism and utopia..." (Bolelli 2007, 2). But the testing of the truth that comes with pragmatism is nowhere

LeRon James Harrison, Ph.D., visiting assistant professor, Department of East Asian Languages and Literature, University of Oregon, USA; main research field: Premodern Japanese Literature and Martial Arts. 
to be found in his assertion. What Bolelli's discussion of martial arts reveals is that there is the tendency to shape martial arts to be what the speaker needs them to be rather than describe what actually occurs within particular styles. But why do we shape martial arts in this manner and how can we avoid this habit? I posit that the shaping emerges from the term martial art being an oxymoron; the positions that are frequently used in the discussions of martial arts are connected to the oxymoronic nature of the term. I also posit that by seeing the styles as practices, not only do we get a more accurate understanding of the styles we frequently call "martial arts," but we get an understanding of how the term "martial art" may be deployed in a way that actually fits what is occurring and avoids shaping the styles to fit the needs of the speaker.

\section{The Oxymoron Called Martial Arts}

Oxymoron is not a term that is commonly associated with martial arts; in the literature on martial arts, one finds the word paradox more frequently than oxymoron. A Google search of the terms "paradox" and "martial arts" reveals articles with titles such as "The Paradox of Budo" and "The Paradox of Esoteric Martial Arts." But when you start to look at the paradoxes within these works, a certain trait appears. For example, Uchida Tatsuru in "The Paradox of Budo" states the paradox in the following way:

The ultimate aim of budo, Japan's martial arts, such as jujitsu, kenjutsu, jojjutsu and aikido, is not to win, but to erase the subject who wants to win. ${ }^{1}$ Herein lies a paradox: If one pursues to rigorously clear all the technical demands for effectively killing or injuring the enemy in the act of self-defense, it will inevitably lead to self-denial, which would enable one's body to act without giving the enemy any clues of possible action. (Uchida 2001, 24)

Uchida's paradox is this: Pursuing a goal driven by the self will lead to denying the self. This, however, does not constitute a paradox. At best, Uchida's "paradox" is fuzzy logic or fuzzy causality, as how self-fulfillment leads to self-denial is not made clear. In other words, Uchida has mistakenly applied paradox to the above situation. Uchida is not alone in misapplying paradox to the martial arts; Barry Allen commits the same mistake in the abstract to his article:

Martial-arts practice is not quite (like) anything else: It is like sport, but is not sport; it constantly refers to and as it were cohabits with violence, but is not violent; it is dance-like but not dance. It shares a common athleticism with sports and dance, yet stands apart from both, especially through its paradoxical commitment to the external value of being an instrument of violence. (Allen 2013, 241)

Allen mentions one element of the paradox: the commitment of martial arts to being an instrument of violence; the other conflicting half, however, he never mentions. So much like Uchida, Allen mistakenly applies paradox to martial arts. These misapplications arise, I argue, because of the oxymoronic nature of the term martial arts.

In his book The Mystic Fable, Michel de Certeau discusses oxymoron in relation to 16th and 17th century discourses on God. Oxymoron, as de Certeau observes, is "a close relative of antiphrasis and... paradox..." (de Certeau 1992, 143). De Certeau in his discussion of these three terms points out that all three involve contradiction used for different effects. Antiphrasis is the use of words and phrases in a contrary manner for ironic effect; an example of this is calling a six foot six-inch man "tiny." The goal of antiphrasis is to conceal disdain and mockery. Paradox is a contradictory statement that may still be true; for example Gong Sunlong's "White Horse Discourse" opens with the paradoxical claim of "a white horse is not a horse." Paradox uses contradiction to raise questions of "identity and class membership," particularly among the Sophists of Western 
and Eastern philosophy (de Certeau 1992, 143). In light of that, there is not a real sense of contradiction and by extension paradox in either Uchida or Allen's statements.

Oxymoron, according to de Certeau, operates by bringing two terms "together (that are) from a different scale or measure. The terms combined in the oxymoron belong to heterogeneous orders: 'cruelty' is not comparable to 'peace'...." In other words, oxymoron manipulates contradiction; it brings together two different terms and gives them the appearance of contradiction by placing them in proximity. Furthermore, the two different terms are placed together to refer to "a third (term), which is posited as absent." As a result, an oxymoron creates "a hole in language" (de Certeau 1992, 143). This hole is what I believe we encounter with the term martial art. The words "martial" and "art" are not contradictory but appear that way when brought together; in being brought together, they point to some third term that is absent. At the same time language, particularly the deictic function, is destabilized. This is what we see in the application of the term martial art.

Take for example the following statement by the late Brandon Lai: "To me, an art like wushu is not traditional. ${ }^{3}$ To be traditional, you must be effective; wushu has no power in their punches or their kicks. I don't call this a martial art. I don't denounce it, but they will have to change to be considered a martial art" (Gonzalez 1997, 80). Lai's statement has a number of lacunae. He equates traditional with being effective, but never explains why effectiveness and tradition should be linked together. Also Lai's claim that wushu "has no power" in the punches or kicks has no direct proof. He is making references to information he keeps hidden from the reader. This hiding of information fits with another observation of de Certeau's: "The oxymoron stands in sharp contrast to the universe of 'similarity.' It is a lapsus in similarity... It is a deictic: It shows what it does not say." De Certeau points out that oxymoron does not focus our attention to similarity; similarity, instead, disappears from sight. Lai's statement is full of non-identity statements: Wushu is not traditional, not effective, and not a martial art. But if wushu is not traditional, not effective, and not a martial art, then what is it? Lai cannot answer the question his statement raises because identity is rooted in similarity, something he makes absent with his statements. De Certeau observes this absenting of reference in oxymoron by stating: "The combination of the two terms is substituted for the existence of a third, which is posited as absent. (The oxymoron)... opens up an absence of correspondence between things and words" (de Certeau 1992, 143). There is an absence between the term "martial art" and the actual styles that Lai is referring to. Lai can state what a martial art is not, but not what a martial is. Lai is not the only one to face this problem; it is, I believe, endemic to the term and its current usage.

The oxymoronic nature of "martial art" and the absence that comes with it raises a question: If martial art is an oxymoron that destabilizes language, hides similarity, and points to an absence, how exactly can Lai, Uchida, or anyone say anything about martial arts? The answer I wish to propose is that they stabilize the meaning of the term by deploying expertise and recognizing invariants. Steven Sloman advances the ideas of expertise and invariants in his book Causal Models; as he explains:

We have a kind of expertise... that derives from knowing what doesn't change across instances and across time, that is, from knowing what's invariant. Expertise inevitably involves the ability to identify invariants. Experts... can tell you what's important and what's more peripheral because they know what explains the way things are and they know what predicts the way things will be. (Sloman 2005, 14-15)

Sloman explains that by identifying invariants, the things that do not change across time, people can gain ownership and control over the objects they discuss by displaying expertise. But in order to identify invariants, 
one has to look selectively and exclude information or, as Sloman puts it, to "look for... the information that will satisfy our current goals" (Sloman 2005, 14). So while stating the invariants and establishing expertise over a subject, an "expert" will ignore whatever is not pertinent to the goals the invariants lead to.

If we turn back to the quotations, we can see the deployment of invariants and expertise in the negative statements. Lai's statements of non-identity are the deployment of expertise. He is able as an expert to say and identify what is not true about wushu: It is not traditional; it is not effective; it lacks power; it cannot be called a martial art. But as invariants, these statements arise from selective attention. To say wushu is not traditional is to focus on Lai's own style of preying mantis gongfu as fitting the label of traditional and wushu as not fitting that idea. It overlooks what other relationships may exist between "traditional" preying mantis and wushu, especially as wushu has preying mantis as one of the "traditional" forms practitioners can learn. Similarly the invariants of lack of effectiveness, lack of power, and non-martial art status are based on comparing wushu against Lai's own style and selectively overlooking styles such as taiji and capoeira which also may look ineffective or lacking in power. ${ }^{4}$ In deploying expertise, the things the expert overlooks can challenge the invariants. So while expertise and invariants may give the appearance of overcoming the problems of an oxymoron, they in fact only obscure the problems. I believe that the concept of practice allows for a way out of these problems and a way to deploy the term "martial art" without committing these problems. But an earlier deployment of practice with regards to martial arts has a set of problems akin to the oxymoronic problems within martial arts. Before I explain how practice can overcome the oxymoronic nature of martial arts, I wish to examine that earlier deployment and the problems that come with it.

\section{Hackney (and MacIntyre) on Practice and Martial Arts}

The concept of practice and its application to martial art is in fact not a new thing; in 2009 Charles Hackney wrote about practice and martial arts in his article "The Aristotelian Philosophy of the Martial Arts." The next year he expanded the ideas into a book about virtues, ethics, and martial arts called Martial Virtues. At the heart of both works is the ethics of Alasdair MacIntyre, which Hackney sees as shedding light on how we understand the role martial arts play in our lives. Hackney's deployment of MacIntyre's thought to explore martial arts provides a contrast to the statements analyzed in the previous section; however, they come with their own problems that Hackney never considers. I wish to explore Hackney's work and MacIntyre's ideas to serve as a way of introducing my approach to practice and martial arts.

Hackney opens "The Aristotelian Philosophy" with a series of questions and possible answers. "How do we describe our involvement in the martial arts? ('I do Jujitsu three times a week.') Are the martial arts an activity that we do? ('I'm a kickboxer.') Are they something that we are? Are the martial arts a subject that we study? ('I study Goju-Ryu karate.')" The tone of these questions and answers is markedly different from the quotations of Lai, Uchida, and Allen; where these aforementioned speakers give expertise and seemingly dispel questioning, Hackney opens with questions and answers and then examines what the combination says about the martial arts. He observes after the question and answer session "possibilities like these all seem to capture something true, but none are entirely accurate by themselves" (Hackney 2009, 9). This marks another fundamental difference between Hackney and Lai et al.: Where Lai et al. make particular claims that they project as universal through their expertise, Hackney sees those same claims as particular and not completely able of capturing the universal involved in the martial arts. In Hackney's approach, we see a caution and 
inquisitiveness that was absent in the earlier statements; with that caution and inquisitiveness comes a more nuanced approach to examining martial arts.

For all the mistakes that Hackney avoids he nevertheless selectively approaches martial arts. The question that drives him is not "How should we talk about martial arts?" but rather "How do we best describe the role martial arts have in our lives?" MacIntyre's work After Virtue provides Hackney with the answer. At the beginning of his discussion of MacIntyre and the Neo-Aristotelian view in After Virtue, Hackney presents the concept of telos (end, goal, purpose). He explains 'the word telos is translated as 'end,' 'goal,' or 'purpose,' and it is the answer to questions such as 'what is this object for?' or 'what does it do?' The telos of a clock is to tell time. The telos of a wolf is to hunt as a member of a pack. The telos of an apple tree is to produce apples" (Hackney 2009, 10). Hackney has selectively overlooked a distinction among the objects he discusses; the clock is an inanimate object while the wolf and the tree are animate. With animate beings, we are much better off speaking in terms of ontology, that is, how they exist in the world rather than teleology. And following anthropologists such as Bjørnar Olsen, we should include the clock in the realm of ontology and not teleology: "I do believe the material world exists and that things constitute a fundamental and persistent foundation for our existence. Things, materials, and landscapes possess real qualities affecting and shaping both our perception of them and our cohabitation with them" (Olsen 2013, 4). So by adopting the concept of telos, Hackney is reducing the complexity of human existence and martial arts down to means and ends.

Another problematic term in Hackney's article is eudaimonia, the Greek word for "happiness" which Hackney explains "refers to a complete human life lived at its best" (Hackney 2009, 11). Eudaimonia itself is not a problem, but Hackney's description of martial arts as "a eudaimonic practice" is. In the conclusion, Hackney asserts "what makes an activity a eudaimonic practice... is the fact that cultivating the qualities of excellence within the practice is connected to becoming a more mature human being" (Hackney 2009, 15). Hackney makes this claim without considering the fights and vitriol that appear in martial arts such as within the Lai quotation. The term martial arts and the absence of meaning and definition that emerge from its oxymoronic nature have led to decrying and bashing various styles; this decrying and bashing seem antithetical to the "happiness" conveyed by eudaimonia. For example, wushu practitioners (myself included) are quite happy when we are allowed to practice; we are not happy with bashing from Lai and others. This actual situation of martial arts appears nowhere in Hackney's discussion of neo-Aristotelian philosophy and martial arts and as a result weakens the claim.

The term that is most relevant to this discussion - practice - is not immune to the problem of overlooking the actual state of affairs in martial arts. The definition of practice appears, as Hackney notes, in the following cumbersome way in MacIntyre's After Virtue:

A practice is any coherent and complex form of socially established cooperative human activity through which goods internal to that form of activity are realized in the course of trying to achieve those standards of excellence with are appropriate to, and partially definitive of, that form of activity, with the result that human powers to achieve excellence, and human conceptions of the ends and good involved, are systematically extended. (MacIntyre 2007, 187; Hackney 2009, 12)

Hackney breaks down MacIntyre's definition of practice into the following elements:

(1) A practice is social in nature;

(2) People get certain benefits from engaging in a practice;

(3) A practice may be described in terms of external and internal goods; 
(4) A practice involves the pursuit of excellence.

Hackney argues that each of these elements is present in martial arts; the question that he does not consider is how accurately the definition of practice advanced by MacIntyre fits with the perception martial artists have of their own martial art.

The first, second, and fourth principles of Hackney's dissection of practice seem accurate; the third, however, seems problematic. If we return to MacIntyre's definition, one notices that it contains an emphasis on interaction, particularly the phrase "socially established cooperative human activity." This phrase implies that a practice is an activity with rules and regulations set down by and carried out in a group of people. This raises the problem of an individual carrying out the activity on their own. More specifically, if an individual should engage in the activity by their self, would MacIntyre recognize the individual as being engaged in the practice? This is an important question to consider with regards to martial arts as throughout the history of martial arts individuals have trained on their own apart from other practitioners. MacIntyre himself is not focused on this question as he is defining practice as part of his larger task of describing virtue. But if we look at the definition, the most likely answer is that MacIntyre would not see an individual alone as engaging in a practice due to the lack of a group to meet the condition of a socially established cooperative human activity. Nevertheless, the fact that a practice is an activity allows for practice to be an action that an individual undertakes by himself. So in describing martial arts in terms of MacIntyre's definition of practice, Hackney is overemphasizing the social and communal nature of martial arts and ignoring the role of the individual in the practice.

Equally problematic in the MacIntyre definition of practice is the discussion of external and internal goods. The use of external and internal goods simply may not be conducive to explicate how martial artists themselves view their own practice. Hackney gives a list of these goods. As external goods, Hackney gives "an increased ability to defend oneself, physical fitness, the feeling of 'living history' that comes from participation in an activity with a rich tradition, enjoyable competition, and spiritual growth;" as internal goods, Hackney lists "a particular kind of spiritual growth" that emerges from mastering the self and "competitive camaraderie" (Hackney 2009, 14). However, a martial artist may not be as inclined to see these as "goods," nor as involving an external/internal distinction. A martial artist (particularly a philosophically minded one) might argue that where Hackney and MacIntyre see goods external and internal to a martial art, one can see effects that arise from the fundamental nature and existence of martial arts. Where Hackney and MacIntyre see ethics a philosophically minded, martial artist might see ontology.

Another way to present the problem inherent within the concepts of external and internal goods is that they may be, in the words of George Lakoff and Mark Johnson, metaphors martial artists do not live by. As they explain in Metaphors We Live By, "the essence of metaphor is understanding and experiencing one kind of thing in terms of another" (Lakoff and Johnson 2003, 5). In the case of external and internal goods, Hackney commits to thinking of martial arts as an exchange where the practitioner gives certain goods and in return receives other reciprocal goods. MacIntyre commits to the metaphor of "a practice is an exchange" as it fits with the social and communal nature of his definition; this sets up the biggest challenge to Hackney's application of practice to martial arts: the solo practitioner. According to MacIntyre's definition, a martial artist who trains on his own is not engaged in the practice of martial arts as there is no exchange of internal and external goods going on, nor is there a social, communal activity being carried out. This exclusion does not only apply to solo training in techniques and forms but also to solo cardiovascular and strength training, which a martial artist would tend to include for the improvements in technical ability that come with them. So while 
MacIntyre's conception of practice may represent a way to resolve the "conflict between describing the meaning of the martial arts as a system of combat, a method of cultural expression, or a spiritual path" to Hackney, there are problems with MacIntyre's conception that Hackney never considers (Hackney 2009, 15). Having laid out these problems, I wish to propose a different conception of practice —one that follows ideas espoused by Todd May and Noël Carroll—as being an alternative that better describes martial arts.

\section{The May-Carroll Version of Practice}

The definition of practice advanced by MacIntyre and Hackney is one focused on ethical issues; what I believe is more fruitful for the styles called "martial arts" is a definition of practice that can account for what occurs within them. I will propose that the definition of practice advanced by Todd May and amended with ideas from Noël Carroll is capable of this task. In his book Our Practices, Our Selves, May defines practice as "a regularity (or regularities) of behavior, usually goal-directed that is socially normatively governed." May goes on to explain the three conditional elements of the definition: goal-directedness, social governance, and normative governance. Goal-directedness means that "most practices have some aim in view;" social governance describes practices as having "roles (that are) masterable by others;" and normative governance refers to "there (being) right ways and wrong ways of engaging in the practice" (May 2001, 9-11). To restate May's definition in light of these explanations, a practice is a regularity or regularities of behavior that: (1) usually have an aim in mind; (2) have right and wrong ways of engagement; and (3) have roles can be mastered by individuals. May's definition presents the role of the individual in practice in ways that MacIntyre never does.

As stated in the previous section, MacIntyre's definition emphasizes the communal nature of practice and overlooks the individual. May, in contrast, begins with the individual by positioning a practice as regularity of behavior. Practice to May is not merely an activity or action; it is a behavior that a person engages in on a recurring basis. As such, May asserts that practices "play (a role) in determining who we are" and later supports this claim in the following way:

A practice in which people engage for 40 hours a week or so would seem likely to make a significant contribution to how they see themselves and their world and how they act in it, even during off hours. What's more, think of how difficult it often is to distance oneself from one's job... Jobs have a tendency to follow us around after work. Not only do we think about the job itself- the work, we also think in terms of the practice that job involves, terms that it usually takes effort and discipline to overcome. (May 2001, 25)

Practice, in May's observation, is not an activity that we can engage in and leave behind; it in fact influences how we think about things inside and outside the practice. The fact that a practice is something we regularly engage in means we cannot easily separate ourselves from the action. Practices are constitutive of who we are. We can sum up May's argument with the phrase "the practice is personal." This is an observation that neither MacIntyre nor Hackney recognizes.

"The practice is personal" dictum explains the vitriol and fighting in martial arts that Hackney overlooked. The negative statements made about a particular style are never taken as strictly about the style. As May suggests, they are interpreted as statements about the practitioner(s) as much as the style. This only fuels the fighting, as the response will be filled with an equal (if not larger) amount of vitriol. Martial arts as a practice have a capacity to bring happiness; however, there is equally the capacity for unhappiness due to the practice being so intimately connected to how a martial artist constitutes their self. 
To apply May's definition to any martial art, we must identify the regularities of behavior, goal orientation, normative governance, and social governance. The regularities of behavior of a martial art consist of the skills and techniques that practitioners work on improving. May describes this idea using Gilbert Ryle's concept of know-how:

Know-how is the mastery of something that requires practice (in the sense of study and repetition) in order to be good at a particular practice (in the sense that this book is exploring)... Being good at a practice demands practice, demands the development of a certain know-how that enables one to engage in the practice successfully. (May 2001, 66; 67)

In this light, the techniques (punches, kicks, joint locks, throws, etc.) and the forms constitute this kind of know-how and the regularities of behavior. The normative governance emerges out of those regularities; the right and wrong ways to execute the various techniques are the normative governance. But this indicates that the normative governance among martial arts will be different as different styles will have different governance over how kicks, punches, and throws are to be executed.

The social governance also varies from style to style; however, as May points out "practices involve... roles, or normatively governed places in which people engaged in the practice... for there to be roles, the norms of the roles must be masterable by others" (May 2001, 10). In light of May's statement, we can recognize that ranking systems such as belts in Japanese and Korean styles and the duan system in Chinese wushu are the standard forms of social governance in martial arts. ${ }^{5}$ Each level of the ranking system carries with it not only certain knowledge and certain norms, but also certain duties and spells out relationships to ranks above and below. Even if there is no ranking system in the style, a martial art must organize the regularities and normative governance and thereby give rise to its social governance.

The final aspect of May's practice - goal orientation — is the element in martial arts with the greatest range. The goal can be determined by the individual, an instructor or with other practitioners and range from advancing to the next rank to doing well in a tournament. These goals can change over time, something that is lacking in the MacIntyre definition. The reason is that May sees "the concept of practice (lying) at the intersection of the individual and the social. The social aspect of the concept... does not give the members of a society any special power in delegating to its members the say-so over what are and are not practices" (May 2001, 12). In May's notion, the individual and the group of practitioners have an equal stake in setting up goals that the individual then chooses to follow. With all this discussion, the four elements of May's practice can be identified and connected to aspects of the martial arts and we can see martial arts as a practice.

By seeing a martial art as a practice, we can reintroduce the similarity that is lost to the oxymoronic nature of martial arts. As practices, all martial arts share the same four defining elements of a practice. This in turn challenges the lapsus in similarity. May himself asserts the connection among practices using his own discipline of philosophy as an example: "Philosophy, I would argue, is a practice, and in that sense, it is similar to many other practices... Like civil engineering or psychology or history, it does not come to its findings by disengaging itself from the world but instead by engaging the world in its own particular way" (May 2001, 3). May argues here that any practice engages the world at large; this assertion challenges that we should see the relationship among martial arts in terms of differences and negative statements only.

For all the insight May's notion of practice brings, his discussion of practice focuses on the present; there is no extended discussion of the relationship between practice and time. To discuss the past and the role it plays in practice, I turn to Noël Carroll's “Art, Practice, and Narrative." 
Unlike May, Carroll sees a distinction between "practice" and "cultural practice." A practice to Carroll is "an activity that is customarily or habitually undertaken;" a cultural practice is "a complex body of interrelated human activities governed by reasons internal to those forms of activity and to their coordination." To Carroll shaking hands is a practice whereas art is a cultural practice. Carroll's definitions of practice and cultural practice fall in line with MacIntyre's definition of practice. It is not his concept of practice that is important but the discussion of practices and changes over time.

Cultural practices need not be static. They require flexibility over time in order to persist through changing circumstances... Practices sustain and abet change while remaining the same practice. Practices do this by a creative use of tradition, or to put the matter another way, practices contain the means, such as modes of reasoning and explanation, which provide for the rational transformation of the practice. (Carroll 1988, 143)

Carroll argues that practices involve change over time as well as elements that remain the same over time. If we apply this to May's definition, we can say that the four elements of practice- the regularities of behavior, goal orientation, social and normative governance-may remain the same or change over time. Practitioners, according to Carroll, will use the history of the practice to explain and rationalize changes to these elements. With Carroll's discussion of practices and change as an addendum to May's definition, this new version of practice is a concept that I believe describes the various styles of martial arts more accurately.

The value of May's ideas does not stop at his conception of practice as an alternative to the term martial art; he also presents two other concepts - community and culture - that allow us to see martial arts in a different light. He brings these two terms up as "a further step in the process of understanding what a practice is... by 'comparing and contrasting' rather than defining" (May 2001, 48). May defines "community" as "those practices or groups of practices through which people share in expressing or realizing significant aspects of who they are" (May 2001, 53). Another way to rephrase May's idea is that a community is a group of people who through a practice or group of practices express their identity. For martial arts, the community is often the school, club or $d \bar{o} j \bar{o}$ where practitioners train. These sites are where practitioners train and share their identities as martial artists. But these sites are also where we can see variations in the practice. Each school or club will have differences in social and normative governance; differences in ranking systems, organization of training and pedagogy will make each community different. But the communities involved in the practice of a specific martial art will all be tied together by engaging in the same practice. This speaks to another term May brings up to compare and contrast to practice: culture.

Culture is a term that we use in many different ways; May discusses culture using the term subculture to position it vis-à-vis community but never gives a definition. He explains that "what distinguishes a subculture from a community seems to be the number and kind of practices that are shared and the concomitant sense of who one is that is given by that sharing;" he later states that "cultures are extensions of communities" (May 2001, 58, 59). According to May's logic, the practice gives rise to communities and the combination of the practice and communities give rise to culture. Culture is something that extends across the practice and the communities engaging in the practice. This sequence of concepts points to May's conception of culture involving shared elements of practice and the sense of being a practitioner as leading to a possible definition for culture. Culture, as May understands, is the elements of practice - be they regularities of behavior, normative governance, social governance, and/or goal orientation - shared across the communities engaged in the practice. To use Wushu as an example, saluting as a sign of respect, training in punches, kicks, stance work, 
combinations of techniques and forms, and participation in demonstrations and competitions are part of the culture of wushu. These elements are carried out in communities practicing wushu; however, one does not have to engage in every aspect of the culture. It is possible to do the saluting and training in techniques of wushu and not have any goal orientation towards participating in demonstrations and competitions. This is possible because the practice lies at the intersection of the individual and the social; the example given would put the individual above the social. So long as the social element of practice is not completely ignored or divorced from the practice, individuals will engage in the culture of the practice.

May only presents the idea of culture in his work on practice; the ideas of practice, community, and culture when applied to martial arts suggest that there should be another level. If every martial art is a practice with its own communities and a culture that spans those communities, then there should be something that spans those practices. This is what we imply with the term martial art: A grouping or category under which different practices, communities, and cultures can be placed. Following May's idea of culture, I wish to posit the concept of metaculture as that term which spans practices, communities, and cultures. The concept of metaculture, much like the concept of practice, has been advanced by other authors, in the case of metaculture by Greg Urban. And much like practice, Urban's definition has its problems. Urban defines culture as "whatever is socially learned, socially transmitted" and metaculture as "culture that is about culture" (Urban 2001, 2; 3). These broad definitions often carry with them misreadings of cultural objects and texts. ${ }^{6}$ Having defined culture as the elements of the practices shared across communities engaged in practice, Urban's tautological definition will not work in this case.

Metaculture needs to be akin to the concept of metageography as discussed by Martin Lewis and Kären Wigen. They explain "by metageography we mean the set of spatial structures through which people order their knowledge of the world: the often unconscious frameworks that organize studies of history, sociology, anthropology, economics, political science, or even natural history" (Lewis and Wigen 1997, ix). In the same vein, I would argue that metaculture is the structures through which we organize practices, communities engaged in those practices, and the cultures emerging from practices. If metaculture is taken as the shared elements of culture among a set of cultures, we end up with a simplified view of both culture and metaculture akin to Urban. To avoid that kind of reductionism, we need to recognize that culture is interconnected with communities and practices and reflect that in metaculture.

The distinction between the reductionist and interconnected view of metaculture takes us back to the term martial arts and its usage. Martial arts as a term is current deployed as a metaculture with a reductionist view. It does not try to incorporate the complexity of the different styles and communities engage in practices; rather it takes a top down approach, seeking to define largely in negative terms and make the various styles fit into that definition. This approach will never accurately capture the practitioners, communities, and cultures that constitute the metaculture known as "martial arts." The approach that emerges from practice is a bottom up approach. It begins by identifying the elements of the practice of a particular style, the communities engaged in the practice and the culture that is shared by these communities. From there we must begin to identify the same for other styles and in doing so being to work out the metaculture that can be called martial arts. Unlike the reductionist approach with its deployment of expertise and invariants, the interconnected approach to metaculture is a much longer and time consuming task as it requires working out a great deal of information with greater detail; however, with the work it comes a more accurate and equitable understanding of the styles 
and the relationships among them. This is what the term "martial arts" should convey: the relationships among the various styles in as accurate and equitable manner as possible.

\section{Conclusion}

The discussion of "martial art" as an oxymoron and practice as an alternative is not meant to replace and dispose the term "martial art" but to (re)connect the term to the actions martial artists take. In making this connection, the practice discussion is in accord with an observation that Mark Johnson makes at the start of his book The Meaning of the Body. Johnson states that meaning is more than words and deeper than concepts; meaning, to him, is not rooted in words, concepts, and propositions but rather "is relational (and) is about how a thing relates and connects with other things" (Johnson 2007, 10). In seeing the combative styles labeled as "martial arts" as practices, my assertion is for a shift away from the conceptual view of these styles to a relational view. A place to see the differences between the two views us the debate over whether styles such as Russian sambo, French savate, and Western boxing should be seen as martial arts. ${ }^{7}$

The current version of the debate has centered on location; the conceptual understanding of martial arts privileges combative styles from Asia, where philosophy is as much a part of the styles as combative techniques. In other words, sambo, savate, and boxing are not martial arts because philosophy is absent from these particular styles. The relational view of the same issue acknowledges the similarities and the differences between styles. For example, sambo may be Russian in origin but it shares grappling techniques with Japanese judo; savate may be French in origin but has similarities with Muay Thai kickboxing. The relationships among styles start to become apparent when we see styles as practices and see the similarities as well as differences. This relational approach, which draws upon philosophy for its insight, follows the observation of Johnson: "It helps to reestablish our visceral connection to ourselves, to other people, and to the worlds. It should help us rediscover the experiential depth to the situation we find ourselves in, so that we can base our inquiry and decision on an appropriately complex understanding... of what we are encountering" (Johnson 2007, 282). The absence of the relationships among martial arts and martial practitioners and the task of exploring the connections among styles and their practitioners are something that can come back to the forefront of a discourse on martial arts with the introduction of practice and the reintroduction of philosophy.

\section{Notes}

1. Jujitsu (Jiu jitsu) is a Japanese martial art centered on throwing, trapping, and joint locking techniques to neutralize an opponent. Jujitsu is the basis for judo and a component of mixed martial arts. Kenjutsu is the general term for Japanese swordsmanship. Under the heading of kenjutsu are styles that lead to the development of kendo and iaido, the martial art focused on drawing and cutting with the Japanese sword. Jōjutsu (Jōdō) is a Japanese martial art focused on the use of the short staff or jo. A jo is anywhere from three to five feet in length and is used to parry and defend against attacks. Aikido is the martial art developed by Morihei Ueshiba that focuses on redirecting the force of an attack.

2. Gong Sulong (c. 325-250 BCE) was a Chinese philosopher during the Warring States period known for a set of essays that explore paradoxes. The "White Horse Discourse" (Baimalun) is one of his extant essays that explore the premise of accepting that a white horse is not a horse by exploring the part/whole relation between "horse" and "white horse."

3. Wushu is a form of Chinese martial arts developed in the 1950s to standardize the traditional styles of martial arts known as gongfu (or kung fu). Wushu incorporates elements from Beijing opera and gymnastics to the empty hand and weapon forms of gongfu; as a result gongfu practitioners often criticize wushu for the incorporation of these non-combative elements.

4. Taiji (Tai chi, taijiquan, or tai chi chuan) is a Chinese martial art that is known for its slow movements. Taiji has gained popularity outside of China for its health benefits. Capoeria is a martial art that developed in Brazil among African slaves. It combines dance and acrobatics with combative techniques to originally disguise techniques that helped slaves escape. 
5. Japanese and Korean martial arts use a ranking system involving a set of colored belts with black being the color indicating the highest rank. The system is made up of grades (kyu in Japanese, geup in Korean) and ranks (dan in Japanese and Korean) with the grades being assigned colors. Chinese martial arts do not consistently use ranking systems; wushu, as a standardized form of martial arts, has recently developed a ranking system using duan (the Chinese pronunciation of dan). There are no belts in the system, rather each duan has a specific set of knowledge; practitioners must master to achieve the rank.

6. An example of Urban's misreading is his interpretation of the 1980 film The Gods Must Be Crazy. Urban describes the scene in which a pilot drops a Coca-Cola bottle into the Kalahari Desert and a bushman picks it up and takes it to his village as a moment of cultural exchange. This overlooks the juxtaposition of the urban lifestyle and the Bushman lifestyle that the movie hinges on as well as the lack of interaction in the transfer.

7. Sambo is a martial art developed in the Soviet Union in the 1920s for the Soviet army; it combines grappling and wrestling techniques from the Soviet Union and Japanese judo. Savate is a French martial art which combines Western boxing with kicking; it emerged from French sailors who combined boxing techniques with the Khmer martial arts they encountered in colonial Southeast Asia in the 19th century.

\section{Works Cited}

Allen, Barry. "Games of Sport, Works of Art and the Striking Beauty of Martial Arts." Journal of Philosophy of Sport 40.2 (2013): 241-54.

Bolelli, Daniele. On the Warrior's Path: Philosophy, Fighting and Martial Arts Mythology. 2nd Edition. Berkeley: Blue Snake Books, 2008.

Carrol, Noël. “Art, Practice, Narrative.” Aesthetics and the Histories of the Arts. Spec. issue of The Monist 71.2 (1988): 140-56.

De Certeau, Michel. The Mystic Fable. Trans. Michael Smith. Vol. 1. Chicago and London: The University of Chicago Press, 1992.

Gonzalez, Michael. “Traditionalism: Will It Survive in America?” Inside Kung Fu Magazine 24.1 (1997): 76-82.

Hackney, Charles. "The Aristotelian Philosophy of the Martial Arts.” Journal of Asian Martial Arts 18.4 (2009): 8-17.

---. Martial Virtues: Lessons in Wisdom, Courage and Compassion from the World's Greatest Warriors. North Clarendon: Tuttle Publishing, 2010.

Johnson, Mark. The Meaning of the Body: Aesthetics of Human Understanding. Chicago and London: University of Chicago Press, 2007.

Lakoff, George and Mark Johnson. Metaphors We Live By. Chicago and London: University of Chicago Press, 2003.

Lewis, Martin and Karen Wigen. The Myth of Continents: A Critique of Metageography. Berkeley and Los Angeles: University of California Press, 1997.

MacIntyre, Alasdair. After Virtue: A Study in Moral Theory. 3rd Edition. Norte Dame: The University of Norte Dame Press, 2007. May, Todd. Our Practices, Our Selves: Or, What It Means to Be Human. University Park: Pennsylvania State University, 2001.

Olsen, Bjørnar. In Defense of Things: Archaeology and the Ontology of Things. Lanham: AltaMira Press, 2013.

Palmer, Richard. Hermeneutics: Interpretation Theory in Schleiermacher, Dilthey, Heidegger, and Gadamer. Evanston: Northwestern University Press, 1969.

Sloman, Steven. Causal Models: How People Think about the World and Its Alternatives. Oxford and New York: Oxford University Press, 2005.

Uchida, Tatsuru. “The Paradox of Budo.” Japan Quarterly 48.1 (2001): 24-30.

Urban, Greg. Metaculture: How Culture Moves through the World. Minneapolis: University of Minnesota Press, 2001. 